\title{
Faciologia e Análise Tectônica Preliminar da Formação Barreiras no Litoral Sul do Estado da Bahia, Brasil
}

\author{
Carlos César Uchôa de Lima' (uchoa@uefs.br), Geraldo da Silva Vilas Boas², Francisco Hilário Rego Bezerra ${ }^{3}$ \\ 'Área de Geociências - DEXA - UEFS \\ Km 3 BR 116, CEP 44031-460, Feira de Santana, BA, BRA \\ ${ }^{2}$ Centro de Pesquisa em Geofísica e Geologia - IGEO - UFBA, Salvador, BA, BRA \\ ${ }^{3}$ Departamento de Geologia - CCET - UFRN, Natal, RN, BRA
}

Recebido em 26 de janeiro de 2006; aceito em 20 de junho de 2006

Palavras-chave: Formação Barreiras, depósitos fluviais, canais entrelaçados, juntas, neotectônica.

\section{RESUMO}

Muitos pesquisadores têm interpretado os sedimentos da Formação Barreiras como um resultado de fluxos gravitacionais, pela quase completa ausência de estruturas sedimentares hidrodinâmicas. Propõem também pouca ou nenhuma deformação nesta unidade. O presente trabalho trata da associação de litofácies, como também dos aspectos estruturais da Formação Barreiras na costa sul do Estado da Bahia, Brasil. A observação acurada de muitos afloramentos revelou que as fácies da Formação Barreiras na região são tipicamente fluviais, de canais entrelaçados. As imaturidades textural e mineralógica dos sedimentos mostram que rios pequenos e temporários, fluxos hiperconcentrados e lagos efêmeros predominaram nas fases iniciais de deposição. Canais entrelaçados bem desenvolvidos, com rios maiores, compõem o ambiente principal de transporte e deposição durante as fases intermediária e final de sedimentação. Os trabalhos de campo evidenciaram grande número de juntas com orientação NW-SE e quantidade menor de juntas com direção NE-SW. A determinação preliminar da direção dos esforços, através de sistemas de juntas, indica um campo de tensões neotectônico caracterizado por uma compressão horizontal máxima com orientação NW-SE, compatível com o campo regional determinado por breakouts em poços de sondagens. A análise da rede de drenagem revela a existência de blocos estruturais limitados por grandes zonas de falhas e basculados em diferentes direções.

Keywords: Barreiras Formation, fluvial deposits, braided channels, joints, neotectonics.

\section{ABSTRACT}

Many researchers have asserted that the Barreiras Formation sediments are the result of gravitational flows because of the almost complete absence of hydrodynamic sedimentary structures. These studies have also suggested a non-tectonic origin for this unit. This paper deals with the lithofacies association and structural features of the Barreiras Formation along the southern coast of the State of Bahia, Brazil. Outcrop analysis revealed that the Barreiras Formation lithofacies are typically fluvial and are associated with braided channels. Immaturity of the sediments indicates that temporary small rivers in hyperconcentrated flows and playa lakes predominated in the initial stages of deposition. Transportation and deposition during the middle to final stages of the Barreiras Formation were characterized by well-developed braided channels, with larger rivers. Field work revealed a large number of NW-SE oriented joints and a relatively small number of NE-SW oriented joints. Preliminary tectonic stress determination, based on measurements of coeval-joints, indicated that the neotectonic stress field presents a NW-SE-trending horizontal maximum compression, which is similar to the present-day stress field determined by breakout analyses. Analysis of modern drainage patterns indicates that crustal blocks limited by major fault zones have been tilted in several directions. 


\section{INTRODUÇÃO}

A Formação Barreiras constitui depósitos sedimentares de origem predominantemente continental (Bigarella, 1975; Lima, 2002), tendo sido descritos depósitos de origem marinha no litoral do Pará (Arai, 1997), cuja idade tem sido atribuída ao Mioceno (Arai, 2005). Apesar da sua grande extensão ao longo da costa brasileira, desde o Estado do Rio de Janeiro até o Estado do Amapá (Suguio e Nogueira, 1999), seus depósitos ainda são pouco conhecidos, tanto no que diz respeito as suas características sedimentares, quanto as suas características tectônicas. Na região do litoral sul da Bahia (Figura 1), a Formação Barreiras aflora em falésias, entre as cidades de Porto Seguro e Prado. Este trabalho trata da Formação Barreiras no litoral sul do Estado da Bahia, sobre aspectos lito-faciológicos e neotectônicos, que podem ser comparados com depósitos descritos em outras partes do litoral brasileiro.

\section{LITOFÁCIES DA FORMAÇÃO BARREIRAS}

No litoral sul da Bahia, predominam litofácies maciças, embora tenham sido observados também, arenitos laminados e com estratificações cruzadas. As litofácies observadas são descritas a seguir.

\section{Conglomerados maciços sustentados por lama (Cmf)}

A litofácies Cmf (Figura 2a) foi observada em um único afloramento e aparece, em geral, sustentada por matriz arenolamosa, embora, em alguns locais, haja contato entre os clastos. Ocorrem desde pequenos seixos a calhaus arredondados, com até $15 \mathrm{~cm}$ de comprimento, sendo constituídos principalmente por calcarenitos e, mais raramente, por fragmentos de equinodermas do Cretáceo. As camadas formam corpos tabulares que alcançam espessura de até $2 \mathrm{me}$ estendem-se lateralmente por algumas dezenas de metros.

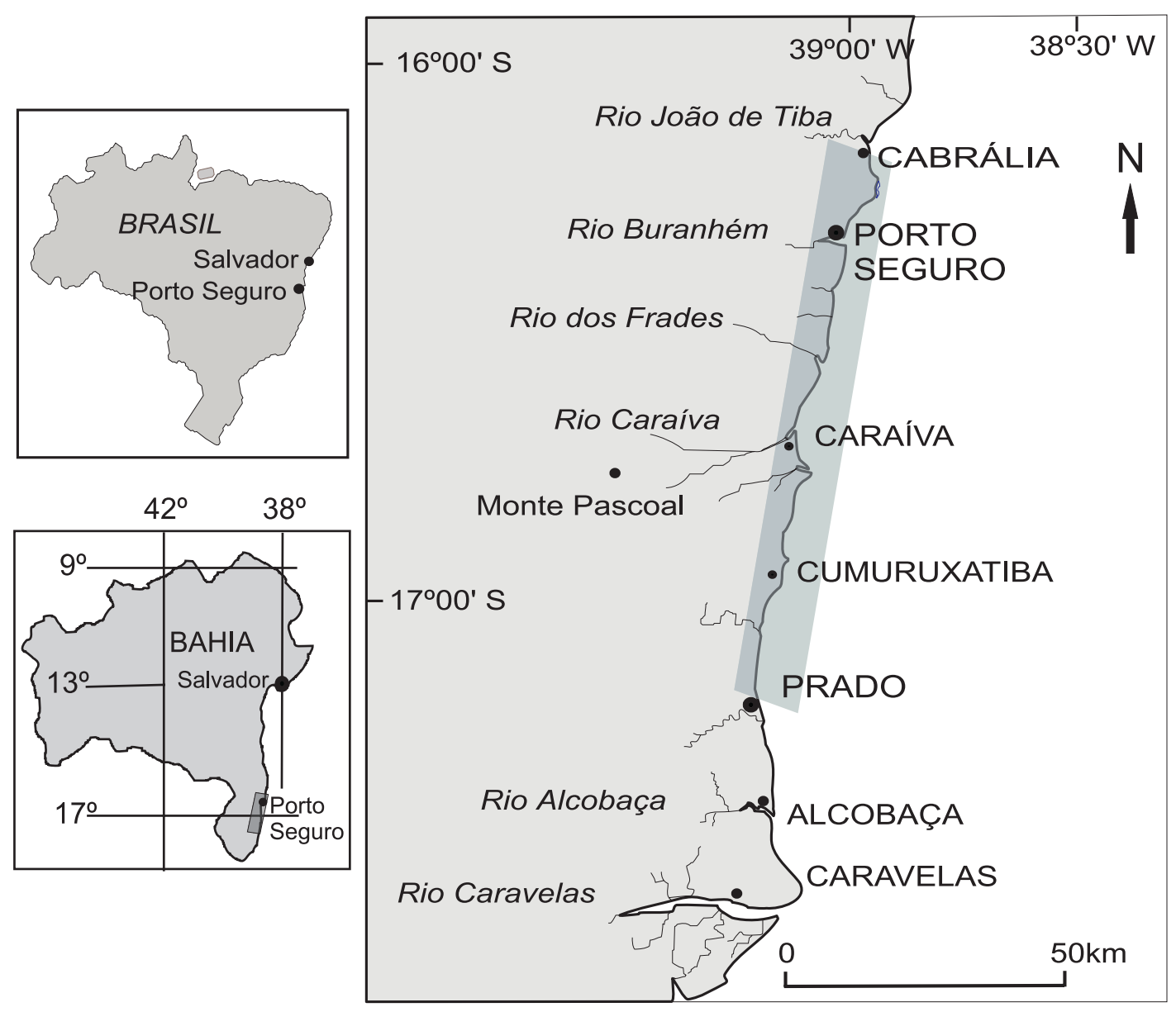

Figura 1. Mapa de localização da área de estudo no sul do Estado da Bahia. Detalhes de localização da área no Brasil e no Estado da Bahia são mostrados à esquerda. 


\section{Conglomerados maciços sustentados por clastos (Cmc)}

Esses conglomerados são constituídos principalmente por seixos que podem ou não estar associados a calhaus intraformacionais e secundariamente por grânulos, com menos de $10 \%$ de matriz areno-argilosa. Os grãos variam de arredondados a subangulosos, e são compostos principalmente por quartzo e secundariamente por feldspatos. Embora maciços na maioria dos afloramentos encontrados, os sedimentos da litofácies $\mathrm{Cmc}$ apresentam granodecrescença ascendente em alguns locais, onde o conglomerado passa para arenito conglomerático e arenito grosso, mal selecionados. As camadas estão dispostas em cunhas com até $40 \mathrm{~cm}$ de espessura e estendem-se lateralmente por alguns metros.

\section{Arenitos maciços conglomeráticos (Amc)}

Esta litofácies é composta por duas variedades diferenciadas pela composição mineralógica: arenitos conglomeráticos quartzosos e arcozianos. Ambas possuem matriz lamosa, são abundantes nas falésias estudadas e contêm grânulos e pequenos seixos imersos. Os grãos são mal selecionados e variam de angulosos a subangulosos e, mais raramente, subarredondados, possuindo, em muitos locais, cimentação silicosa. Os arenitos conglomeráticos arcozianos (Figura 2b) são semelhantes aos quartzosos, exceto pela presença de feldspato, que pode atingir até $40 \%$ do total de grãos. Do ponto de vista estratigráfico, os arenitos arcozianos ocorrem sempre abaixo dos arenitos conglomeráticos quartzosos.

\section{Arenitos maciços lamosos (Aml)}

Esses arenitos possuem granulometria fina a grossa, com grãos angulosos a subarredondados. Esta litofácies apresenta abundante matriz caulínica, sem, no entanto, apresentar grânulos imersos. Os grãos são mal selecionados, constituídos predominantemente por quartzo hialino e secundariamente por fragmentos de argilitos e feldspato caulinizado. As camadas são tabulares e possuem entre 0,5 a $1,2 \mathrm{~m}$ de espessura. $\mathrm{O}$ arenito lamoso pode gradar em sua parte superior para siltito com grãos de areia imersos.

\section{Arenitos com estratificações cruzadas acanaladas (Aa)}

A litofácies Aa (Figura 2c) possui grãos angulosos a subarredondados, é mal selecionada e apresenta predomínio de areia grossa, embora ocorram níveis de areia média a fina. A espessura dos sets individuais pode variar, predomi- nando aqueles que possuem entre 0,2 a $0,4 \mathrm{~m}$ de espessura e extensão de até $2 \mathrm{~m}$. Concentrações de grânulos e seixos aparecem na base de algumas seqüências. As medidas de paleocorrentes indicaram um vetor médio resultante (Curray, 1956) com sentido $113^{\circ}$ azimute (az) e vetor magnitude de $94 \%$, o que mostra um predomínio do direcionamento das correntes para SE.

\section{Arenitos com estratificações cruzadas planar (Ap)}

Essa litofácies caracteriza-se por granulometria fina a grossa. Os grãos são predominantemente subangulosos a subarredondados e compostos principalmente por quartzo e secundariamente por feldspato caulinizado. As seqüências podem aparecer isoladas ou agrupadas em camadas com geometria tabular. As sequiências isoladas exibem até $0,4 \mathrm{~m}$ de espessura e continuidade lateral na ordem de alguns metros.

\section{Folhelhos (Fm)}

Folhelhos de cor cinza escura em camadas tabulares, com até $1 \mathrm{~m}$ de espessura, foram observados em vários afloramentos. Em alguns locais, os folhelhos aparecem associados aos siltitos laminados.

\section{Siltitos laminados (FI)}

Os siltitos (Figura 2d) ocorrem sobrepostos a arenitos, em camadas com até $0,9 \mathrm{~m}$ de espessura. A passagem entre ambos é gradacional, ou marcada por intercalações de folhelhos. Grãos de areia são comumente observados imersos na litofácies Fl.

\section{Siltitos/arenitos rítmicos (Fr)}

Esta litofácies aparece associada à litofácies $\mathrm{Cmf}$ e é composta por siltitos e arenitos finos e laminados, com espessura entre 1 e $5 \mathrm{~cm}$ (Figura 3a). Camadas com alguns decímetros de espessura de arenito fino aparecem, por vezes, intercaladas entre as sequiências rítmicas.

\section{Folhelhos com gretas de contração (Fg)}

O folhelho observado possui coloração cinza esverdeada, com arenito arcoziano preenchendo as gretas de contração. Em perfil, os corpos arenosos que preenchem as gretas de contração se apresentam sob a forma de colunas irregulares e contínuas (Figura 3b). No plano horizontal, ocorrem várias gretas, com diâmetros e espessura de preenchimento variados (Figura $3 \mathrm{c}$ ). 

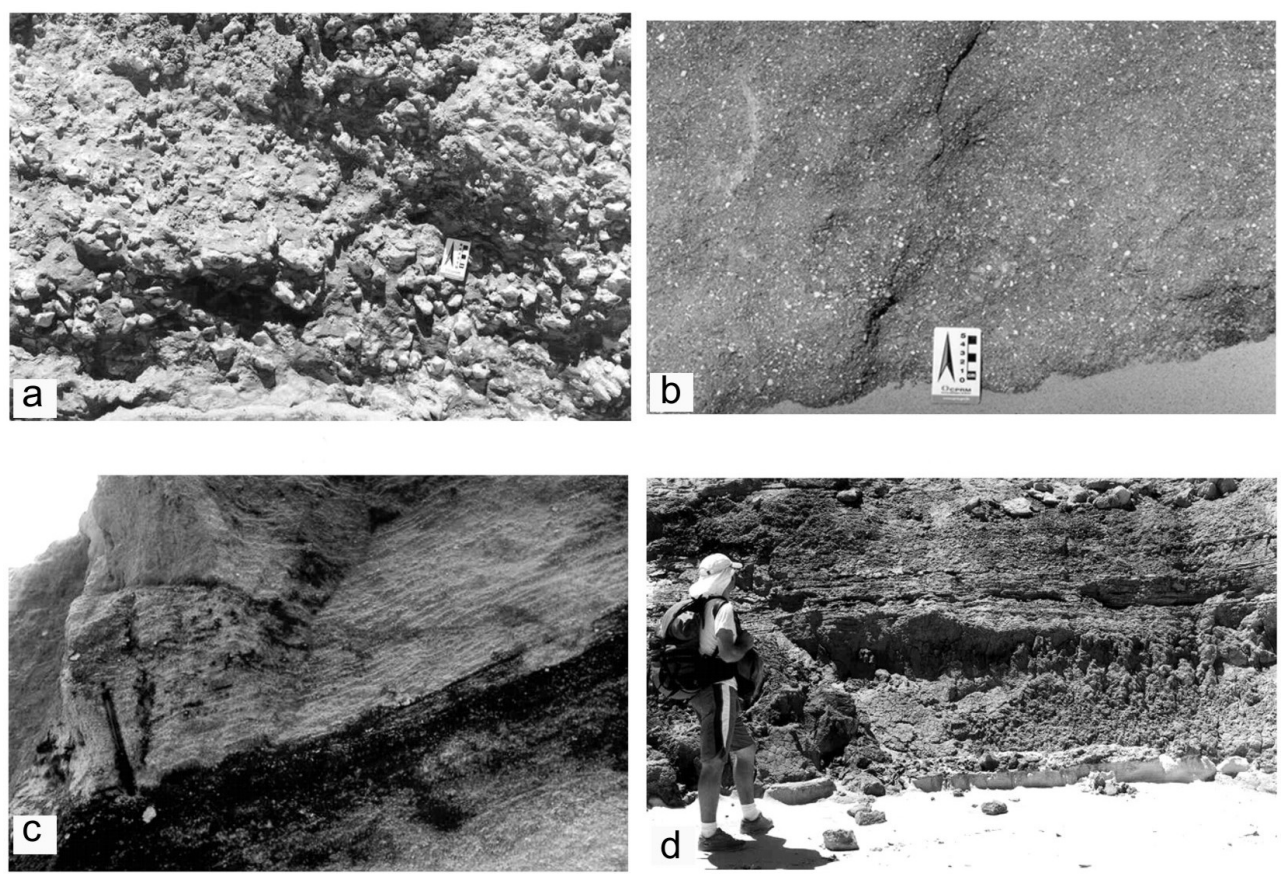

Figura 2. Litofácies da Formação Barreiras. a. Conglomerados maciços sustentados por lama. b. Arenitos maciços conglomeráticos. c. Arenitos com estratificações cruzadas acanaladas. d. Folhelhos e siltitos laminados.
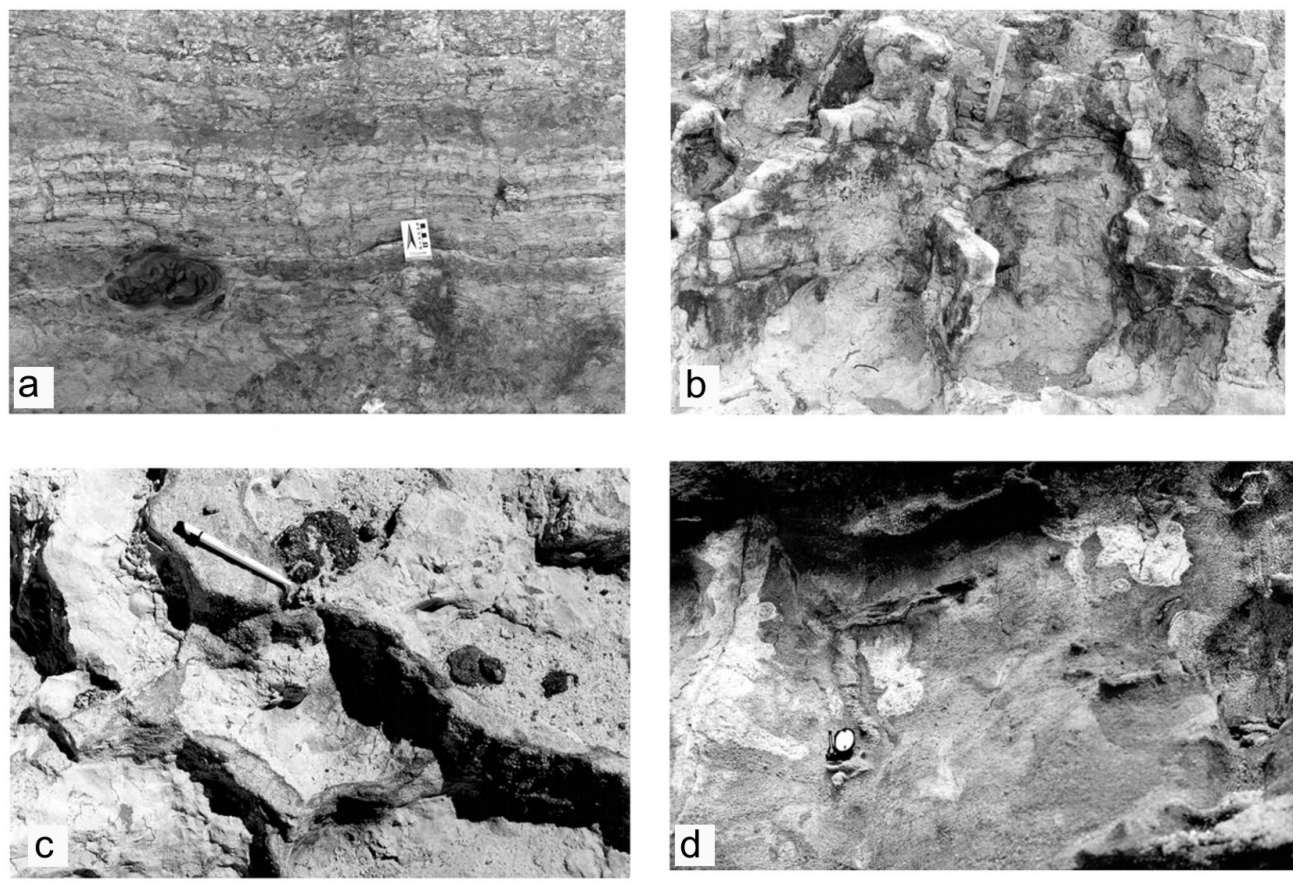

Figura 3. Litofácies da Formação Barreiras. a. Siltitos/arenitos rítmicos. b. Folhelhos com gretas de contração vistas em perfil e preenchidas por arcózio. c. Folhelhos com gretas de contração observados na superfície do terreno (plano horizontal). d. Arenito com feições pedogenéticas. 


\section{Arenitos com feições pedogenéticas (Apd)}

Fácies de arenito grosso com grânulos imersos, mal selecionado, composto de quartzo e feldspato caulinizado. Prováveis traços de raízes com até $15 \mathrm{~cm}$ de espessura (Figura 3d) são preenchidos por areia e cimentados por hidróxido de ferro. Além das paleo-raízes, aparecem também concreções ferruginosas. A espessura máxima observada desse arenito foi de $2 \mathrm{~m}$.

\section{Lamitos com feições pedogenéticas (Fpd)}

Esta litofácies é predominantemente síltico-argilosa e possui uma coloração cinza esverdeada, com algumas manchas amarronzadas atribuíveis a hidróxido de ferro. Próximo ao contato com a camada que a sobrepõe, esta litofácies exibe estrutura prismática.

\section{ELEMENTOS ARQUITETURAIS IDENTIFICADOS}

A continuidade de dezenas de quilômetros de afloramentos da Formação Barreiras na área estudada possibilitou o estudo de elementos arquiteturais, segundo modelos propostos por Miall $(1985,1996)$, que sugere a existência de pelo menos oito tipos básicos desses elementos em depósitos fluviais, identificados a partir da assembléia de litofácies, da geometria interna e da natureza dos contatos superior e inferior que limitam o elemento. Os elementos arquiteturais identificados são descritos a seguir.

\section{Fluxos Gravitacionais de Sedimentos (SG)}

Este elemento arquitetural apareceu nitidamente uma única vez, onde predominam conglomerados com cascalhos de composição carbonática, intercalados com finas camadas de lama. Essas rochas aparecem representadas principalmente pelas litofácies $\mathrm{Cmf}$ (conglomerados maciços suportados por finos) e secundariamente pela litofácies $\mathrm{Cmc}$ (conglomerados maciços suportados por clastos). Os corpos conglomeráticos aparecem em forma de cunha ou lóbulos que, ao se amalgamarem, formam camadas tabulares separadas por finas camadas de lama escura com pequenos seixos imersos.

\section{Formas de Leito Arenosas (SB)}

Este elemento aparece em vários locais, sendo mais facilmente identificado em algumas porções das falésias entre Prado e Cumuruxatiba. Neste elemento arquitetural, a litofácies Aa predomina, embora a litofácies Ap também esteja presente. As superfícies limitantes da base dos elementos SB podem ser acompanhadas por várias centenas de metros. Associações com os elementos FF e CH são muito comuns.

\section{Canais $(\mathrm{CH})$}

Dos elementos arenosos, o elemento $\mathrm{CH}$ é o que aparece com maior freqüência na área estudada. $\mathrm{O}$ mesmo pode ser observado de forma isolada, imerso em pacotes lamosos, ou então apresentar-se com várias superfícies côncavas para cima que delimitam a base de um ou mais canais que migraram durante a deposição dos sedimentos. Os canais observados evidenciam profundidades que variam desde $70 \mathrm{~cm}$, nos canais menores, até mais que $3 \mathrm{~m}$ nos canais maiores. A largura destes canais pode variar de alguns metros, até várias dezenas de metros. Estratos cruzados planares e acanalados (litofácies Aa e Ap) foram observados em muitos canais.

\section{Finos de Transbordamento (FF)}

Os finos de transbordamento aparecem freqüentemente intercalados com os pacotes arenosos (elementos $\mathrm{SB} \mathrm{e} \mathrm{CH}$ ). As litofácies que compõem o elemento são os finos maciços $(\mathrm{Fm})$ e os finos laminados (Fl). Ambos aparecem em abundância, embora os finos maciços estejam em maior quantidade. A espessura das camadas lamosas que compõem o elemento FF pode atingir cerca de $4 \mathrm{~m}$.

\section{PROVÁVEIS AMBIENTES DEPOSICIONAIS}

Segundo vários autores, a Formação Barreiras seria produto da coalescência de leques aluviais e de sistemas fluviais entrelaçados, em clima quente e seco (Mabesoone, Campos e Silva, Beurlen, 1972; Bigarella, 1975). No litoral sul da Bahia, a observação de arenitos maciços constituídos de grãos angulosos e mal selecionados, alguns com faces cristalinas, e a presença de feldspatos nos sedimentos, sugerem, em princípio, transporte e deposição rápidos com retrabalhamento limitado, como em fluxos de detritos ou de lama.

Porém, a ausência de estruturas sedimentares hidrodinâmicas nesses depósitos foi atribuída por Lima (2002) às seguintes razões:

a. o constante desmoronamento das falésias não permite que o intemperismo tenha tempo suficiente para ressaltar as linhas que definem as estruturas primárias (segundo Miall, 1996);

b. o alto índice pluviométrico atual da área estudada ocasiona a formação de uma película de lama que desce pelas paredes das falésias, em dias de chuva, impedindo a observação das estruturas sedimentares hidrodinâmicas;

c. muitas camadas encontram-se oxidadas, mascarando, assim, as estruturas primárias presentes.

As feições canalizadas individuais e amalgamadas presentes em quase toda a extensão da Formação Barreiras, 
além da identificação dos elementos arquiteturais SB (formas de leito arenosas) em alguns locais e dos elementos $\mathrm{CH}$ (canais) e FF (finos de transbordamento) em quase toda a área, revelam que os sistemas fluviais foram os agentes predominantes durante o transporte e deposição dos sedimentos. Associações entre os elementos SB, FF e CH mostram uma íntima associação entre os elementos fluviais arenosos (área de fluxo principal das correntes) e lamosos (áreas de inundação), reforçando a idéia de domínio fluvial para a deposição dos sedimentos Barreiras.

Os fluxos gravitacionais de sedimentos também estiveram presentes, mas é provável que os sedimentos depositados por esses fluxos tenham sido retrabalhados pelos pequenos canais, amplamente registrados nos afloramentos do litoral sul da Bahia. Tendo por base a espessura dos pacotes arenosos que compõem o elemento $\mathrm{CH}$ e a espessura das sequiências individuais (sets) das estruturas sedimentares hidrodinâmicas, os canais deveriam atingir poucos metros de profundidade (cerca de $3 \mathrm{~m}$ ), com largura na ordem de algumas dezenas de metros (Lima, 2002). As observações de campo sugerem que, pelo menos no litoral sul da Bahia, a maior parte dos depósitos é de origem fluvial, em canais entrelaçados.

\section{EVIDÊNCIAS DE TECTONISMO - ANÁLISE PRELIMINAR}

Lima e Vilas Boas (2004) realizaram análise morfotectônica da Formação Barreiras no litoral sul da Bahia. Durante os trabalhos de campo, foram estudadas extensas falésias, onde juntas e algumas falhas indicam atividades tectônicas. A análise de produtos de sensoriamento remoto também sugeriu forte controle tectônico no padrão de drenagem, conforme discussão a seguir.

\section{Evidências morfotectônicas}

A análise morfotectônica permitiu destacar três blocos estruturais (Figura 4), separados por vales situados em baixos estruturais, entre as cidades de Cabrália e Caraíva, conforme os padrões e direções das drenagens, que sugerem a movimentação desses blocos. O estudo dos blocos se tornou possível graças à homogeneidade litológica, a alta densidade das drenagens presentes, além dos altos estruturais serem planos, com sedimentos não dobrados, e cortados por vales escarpados com desníveis topográficos máximos situados entre 40 e $60 \mathrm{~m}$.

A homogeneidade dos sedimentos na região estudada poderia, teoricamente, favorecer o desenvolvimento de drenagem dendrítica. No bloco 1, apesar da maioria dos tributários exibir este padrão, os cursos fluviais mais longos tendem ao paralelismo e apresentam direção $70^{\circ} \mathrm{az}$.

Em contraste com o bloco 1, os rios correm para E-SE $\left(106^{\circ} \mathrm{az}\right)$ no bloco 2. Algumas anomalias de drenagem observadas neste bloco poderiam estar relacionadas a fraturas, evidenciando forte controle estrutural em alguns trechos dos rios.

No bloco 3, a direção média das drenagens segue para $129^{\circ}$ az, com os principais cursos desembocando no Rio Caraíva, indicando basculamento deste bloco para SE. Um dos tributários mais longos do Rio Caraíva possui um curso retilíneo NW-SE, sugerindo que esteja em uma zona de falha.

Essas observações sugerem reativação tectônica póssedimentação, com intensidade suficiente para promover basculamento de blocos e modificar o padrão de drenagem atual, que tenderia a ser dendrítico e não subpararelo, conforme foi observado. Lima e Vilas-Boas (2004) desenvolveram estudos na área e sugeriram que as drenagens, originalmente dendríticas, foram redirecionadas a partir do basculamento de blocos, durante o Quaternário.

A sul de Cumuruxatiba foi observada uma falha com plano subvertical e direção aproximada E-W ocupada por uma queda d'água. O bloco a sul da falha mostra leve basculamento, durante a descida em relação ao bloco norte, conforme as atitudes das camadas. A verticalidade do plano de falha não permite definir se a mesma é normal (gravitacional) ou reversa (acavalamento). Uma estrutura em flor ocorre a norte de Cumuruxatiba, onde as falhas conjugadas, a sul e a norte, possuem mergulhos para $30^{\circ}$ az e $122^{\circ}$ az respectivamente. As falhas estão presentes em afloramento constituído por intercalação de arenitos e lamitos friáveis.

\section{Juntas}

Devido a pouca ocorrência de afloramentos com falhas, medidas de sistemas conjugados de juntas foram usadas para obter, em caráter preliminar, o campo de tensões que afetou a Formação Barreiras nesta parte do litoral brasileiro. Dados de alguns afloramentos considerados representativos, entre Prado e Porto Seguro, mostram dois sistemas de juntas orientados nas direções NE-SW e NW-SE. Os dois sets ocorrem em toda a área, embora o segundo seja mais freqüente entre Caraíva e Porto Seguro. A atitude geral de cada set, em áreas selecionadas, é apresentada na Figura 5. Em geral, as juntas ocorrem na forma de sets conjugados. $\mathrm{O}$ resultado geral dessa análise preliminar apontou sentido de $\sigma_{1}$ para $341^{\circ}$ az com mergulho de $19^{\circ}$ e direção NNW-SSE a NW-SE. Em alguns pontos, entretanto, os sets mostram comportamento de juntas distensionais, indicando eixo de tensão $\sigma_{3}$ subhorizontal e com direção $30^{\circ} \mathrm{az}$.

Os dados de paleotensões aqui observados indicam que a compressão máxima forma um ângulo de $25^{\circ}$ com a costa. Lima, Nascimento e Assumpção (1997) realizaram pesquisas sobre esforços tectônicos ao longo das bacias marginais brasileiras, usando estudos de colapso de poços. Embora esses 

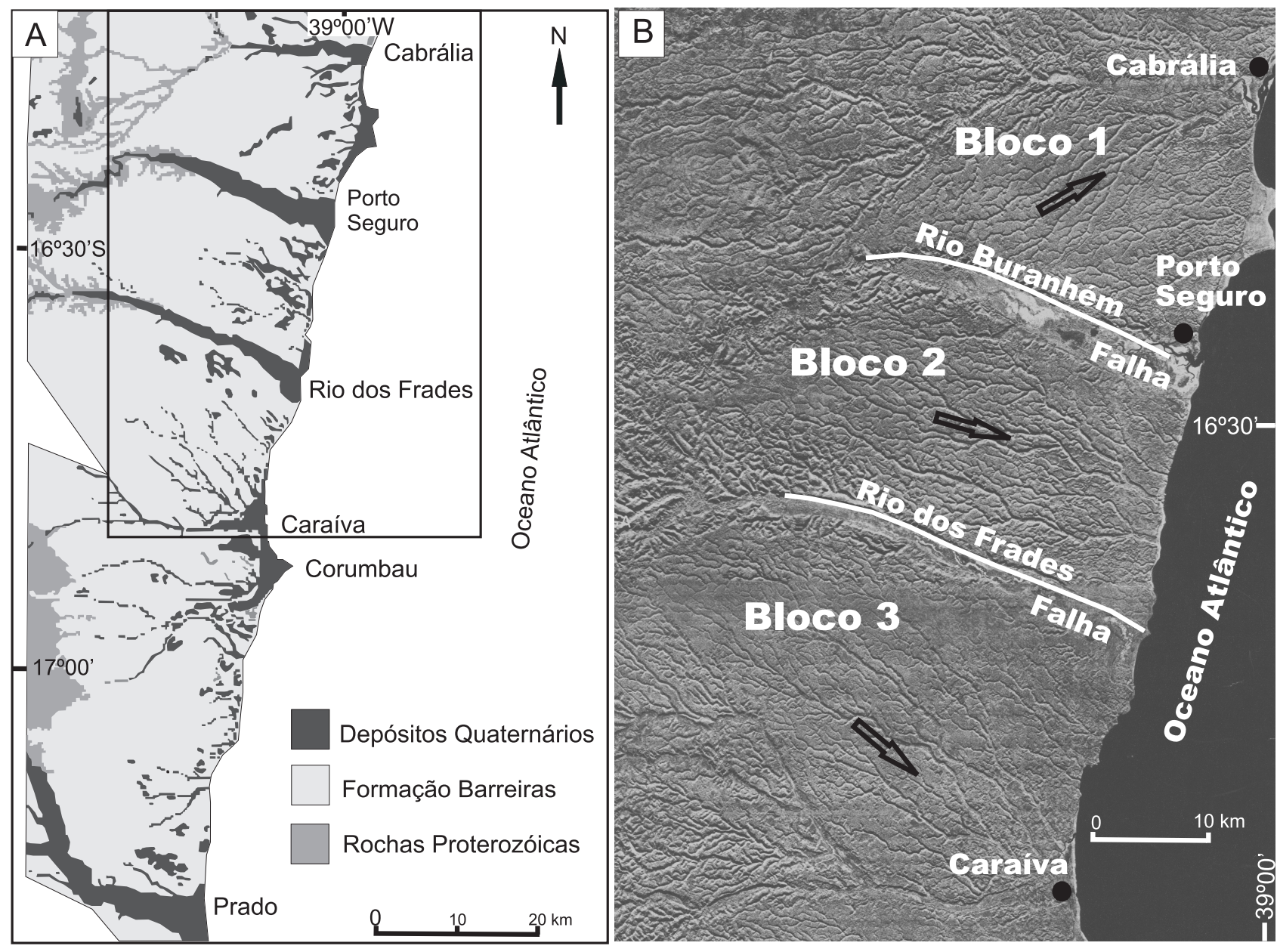

Figura 4. Feições estruturais em escala regional. A. Mapa geológico simplificado da área de trabalho. B. Radar de visada lateral da parte norte da área, apresentando três blocos estruturais. As setas indicam o vetor médio do sentido das correntes para os três blocos estudados.

autores não se refiram aos esforços que ocorrem na Bacia de Cumuruxatiba, os dados por eles apresentados mostram que as tensões nesta bacia possuem direção NW-SE, concordando com os dados preliminares apresentados para a área de estudo do presente trabalho.

\section{CONCLUSÕES}

Foram identificadas duas fases de deposição para a Formação Barreiras no litoral sul da Bahia. Na primeira fase (Figura 6a), foram depositados arenitos arcozianos e argilitos claros, contendo abundantes gretas de contração. Essas características levam à interpretação de que houve o predomínio de canais entrelaçados e, mais raramente, fluxos de detritos em uma planície onde predominou o clima quente e seco. Pequenos lagos temporários (playa) teriam existido, tendo sido submetidos à exposi- ção subaérea, originando as grandes gretas de contração observadas.

A segunda fase deposicional (Figura 6b) é registrada por arenitos e argilitos espessos, que se intercalam. Os arenitos são predominantemente quartzosos e os argilitos, diferentemente dos depositados na primeira fase, não exibem gretas de contração. Nesta fase, apesar da ocorrência de canais menores, canais entrelaçados bem definidos, com até mais que $3 \mathrm{~m}$ de profundidade e largura de algumas dezenas de metros, teriam existido.

O estudo neotectônico preliminar sugere que o campo de tensões é compatível com aquele determinado por estudo de colapso de poços desenvolvido por Lima, Nascimento e Assumpção (1997). Através da mudança de orientação do padrão de drenagem, foram reconhecidos três blocos estruturais separados por falhas ESE-WNW, cuja cinemática é ainda desconhecida. 

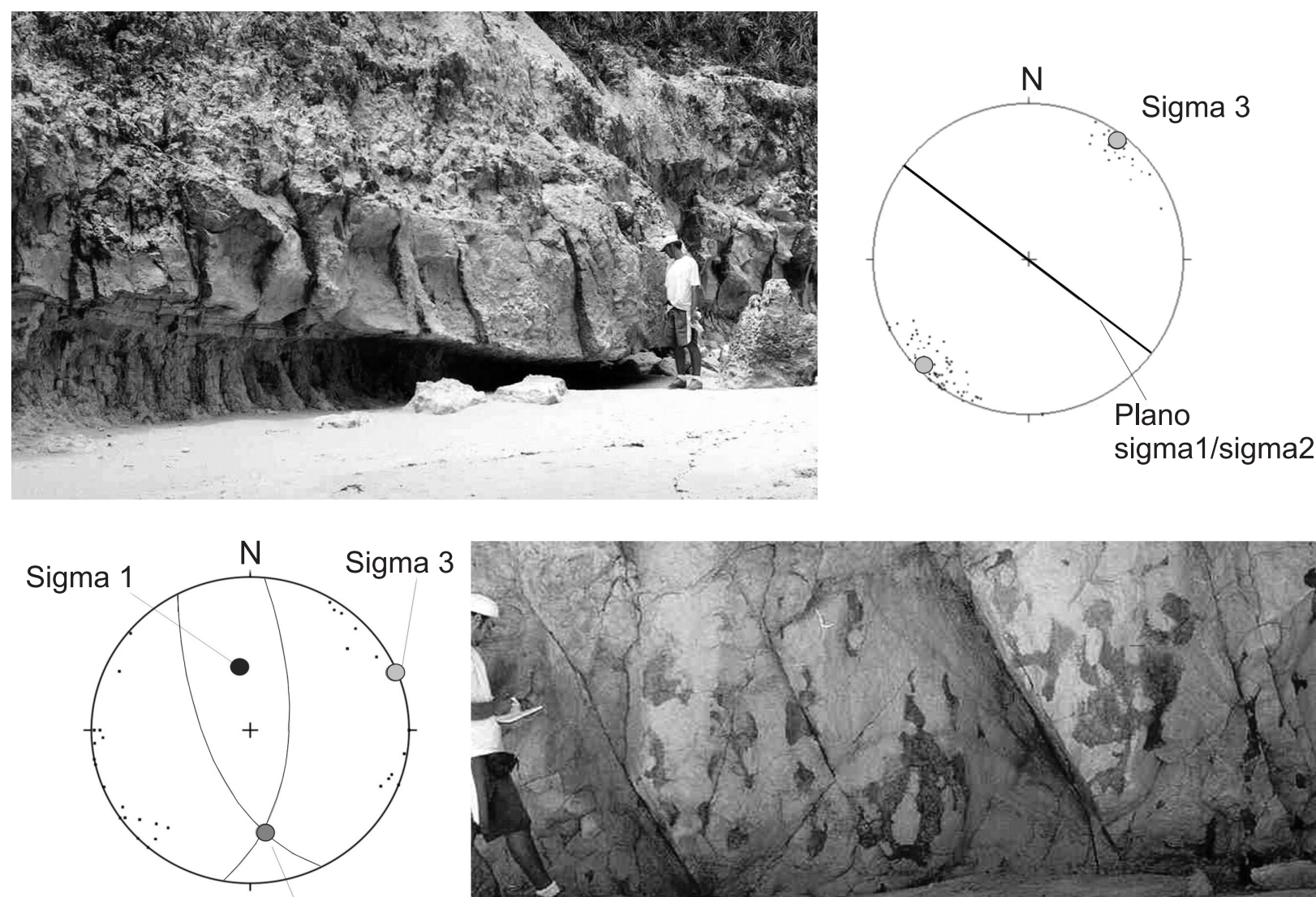

Sigma 2
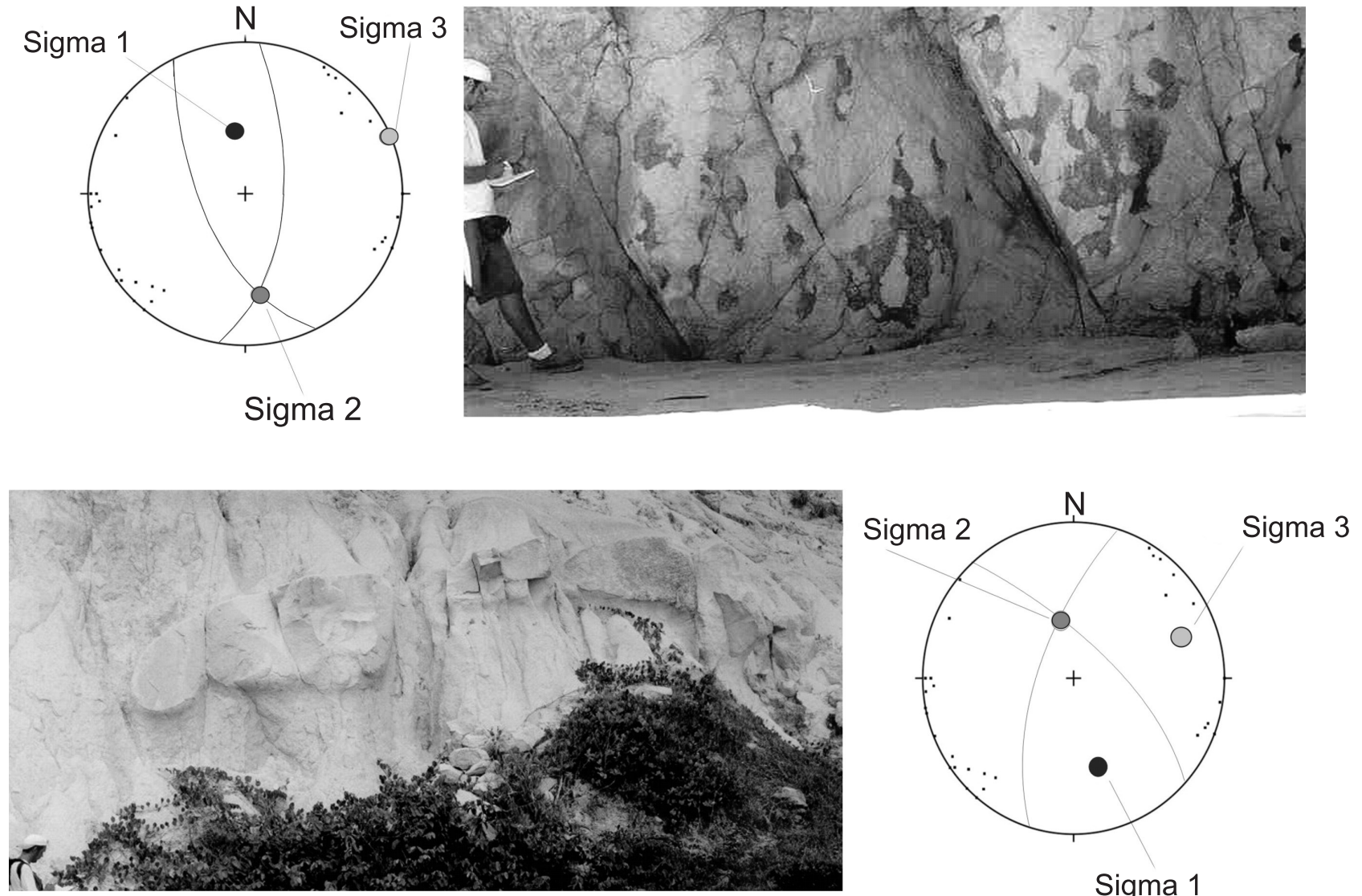

Sigma 1

Figura 5. Sistemas conjugados de juntas tectônicas observadas nos afloramentos entre Caraíva e Porto Seguro. 

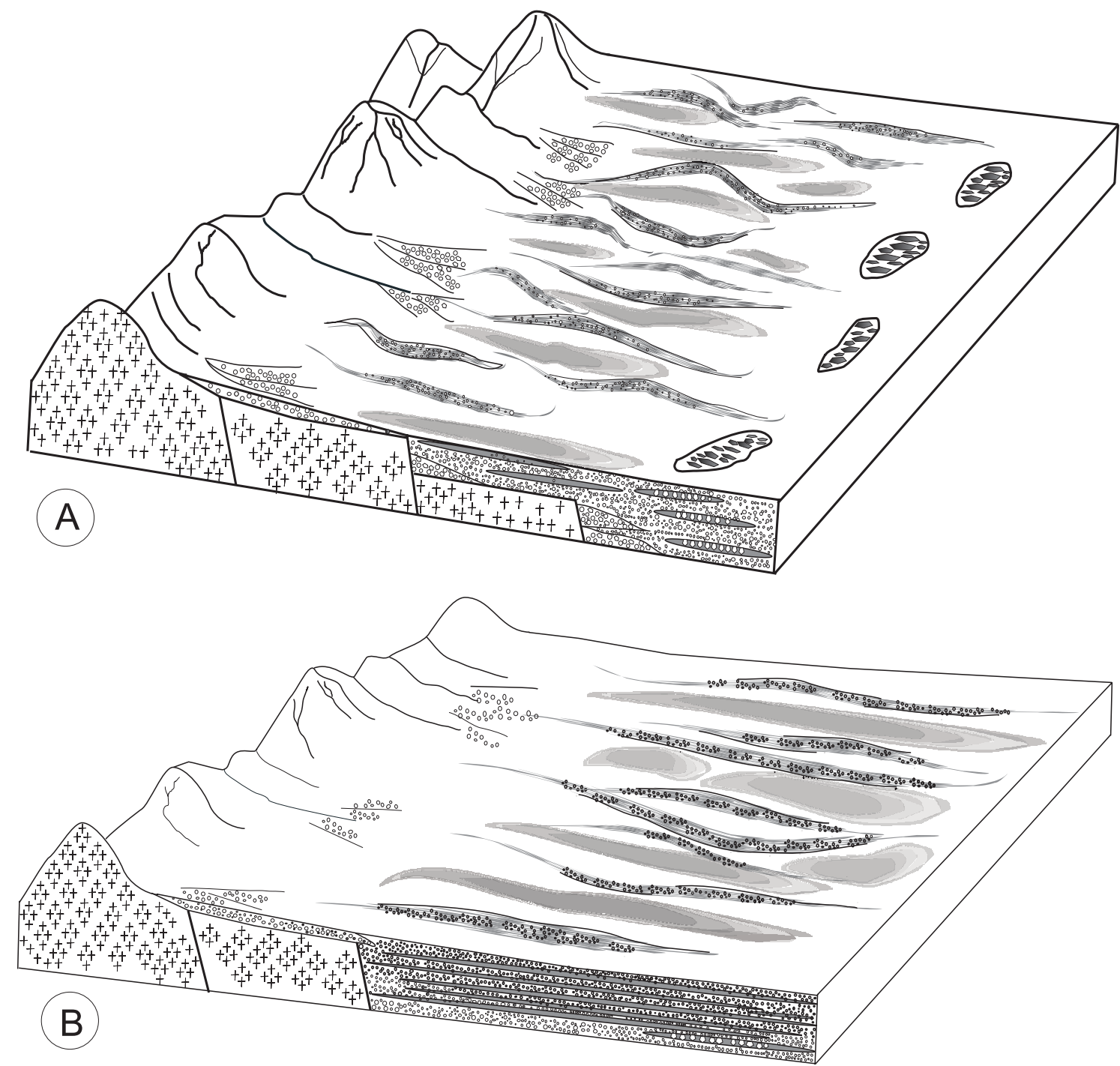

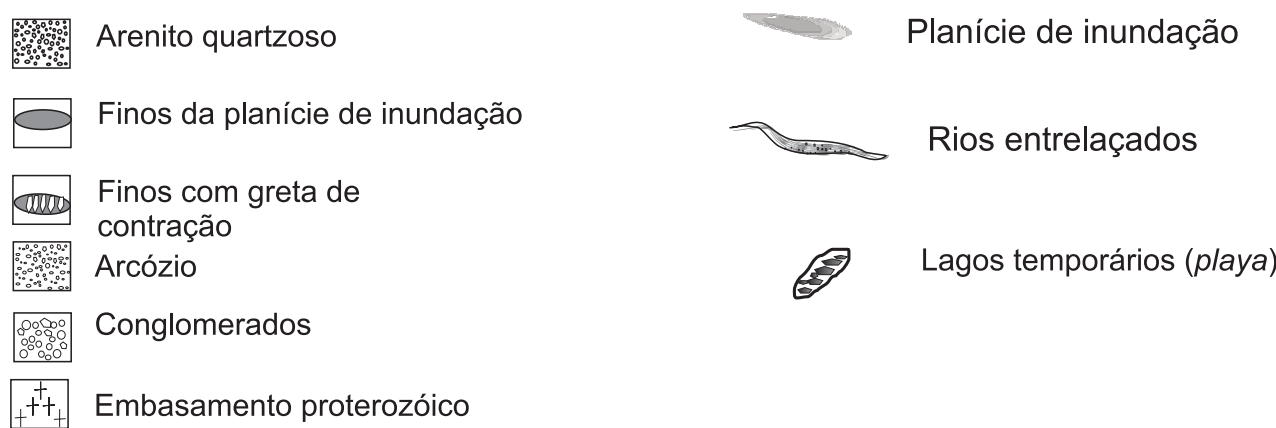

Figura 6. Fases de deposição para a Formação Barreiras. A. Fase inicial, onde predominaram canais entrelaçados e lagos temporários em clima quente e seco. Arcózios e argilitos são as litofácies mais comuns. B. Fase onde predominaram canais entrelaçados maiores, com desenvolvimento de planícies de inundação. Arenitos quartzosos e argilitos são as litofácies predominantes. 


\section{AGRADECIMENTOS}

Expressamos nossos agradecimentos a Kenitiro Suguio (USP, UnG) e a Claudio Limeira Mello (UFRJ) pelas valiosas sugestões para o aprimoramento do presente trabalho.

\section{REFERÊNCIAS BIBLIOGRÁFICAS}

ARAI, M. Dinoflagelados (Dynophyceae) miocênicos do Grupo Barreiras no nordeste do estado do Pará (Brasil). Revista da Universidade de Guarulhos-Geociências, n. 2, p. 98-106, 1997. Número especial.

ARAI, M. A grande elevação eustática do Mioceno: a verdadeira origem do Grupo Barreiras. In: CONGRESSO DA ASSOCIAÇÃO BRASILEIRA DE ESTUDOS DO QUATERNÁRIO, 10., 2005, Guarapari. Anais eletrônicos... Guarapari: ABEQUA, 1996. Disponível em: <http:// www.abequa2005.geologia.ufrj.br/lng/pt/pdfs/ 0310_arai_artigoabequa2005>. Acesso em: 07 ago. 2006.

BIGARELLA, J. J. The Barreiras Group in Northeastern Brazil. Anais da Academia Brasileira de Ciências, v. 47, p. 365-393, 1975. Suplemento.

CURRAY, J. R. The analisys of two dimensional orientation data. Journal of Geology. v. 64, n. 2, p. 117-131, 1956.

LIMA, C. C.; NASCIMENTO, E.; ASSUMPÇÃO, M. Stress orientations in Brazilian sedimentary basins from breakout analysis: implications for force models in the South American plate. Geophysical Journal International, v. 130, n.1, p. 112-124. 1997.

LIMA, C. C. U. Caracterização sedimentológica e aspectos neotectônicos do Grupo Barreiras no litoral sul do Estado da Bahia. 2002. $141 \mathrm{f}$. Tese (Doutorado) - Instituto de Geociências, Universidade Federal da Bahia, Salvador, 2002.

LIMA, C. C. U.; VILAS BOAS, G. S. Morphotectonic analysis in the Barreiras Group, south coast of the state of Bahia, based on the square over radar image approach. Revista Ciência e Natura, v. extra, p. 101-115. 2004. Edição especial.

MABESOONE, J. M., CAMPOS E SILVA, A.; BEURLEN, K. Estratigrafia e origem do Grupo Barreiras em Pernambuco, Paraíba e Rio Grande do Norte. Revista Brasileira de Geociências, v. 2, n. 3, p. 173-188, 1972.

MIALL, A. D. Architectural-element analysis: a new method of facies applied to fluvial deposits. Earth Science Reviews, v. 22, n. 4, p. 261-308. 1985.
MIALL, A. D. The Geology of Fluvial Deposits: sedimentary facies, basin analysis and petroleum geology. New York: Springer, $1996.582 \mathrm{p}$.

SUGUIO, K.; NOGUEIRA, A. C. R. Revisão crítica dos conhecimentos geológicos sobre a Formação (ou Grupo?) Barreiras do Neógeno e o seu possível significado como testemunho de alguns eventos geológicos mundiais. Geociências, São Paulo, v. 18, n. 2, p. 439-460, 1999. 